\title{
The Effect of Using Blackboard on English Majors' Writing Proficiency and Attitudes
}

\author{
Mohamed Ali Mohamed Kassem* \\ Department of Curriculum and Teaching Methodology, Faculty of Education in the New Valley, Assiut University, Egypt \\ Corresponding Author: Mohamed Ali Mohamed Kassem, E-mail: m_kassem1@yahoo.com
}

\section{ARTICLE INFO}

Article history

Received: April 16, 2018

Accepted: July 21, 2018

Published: November 01, 2018

Volume: 7 Issue: 6

Advance access: September 2018

Conflicts of interest: None

Funding: None

\begin{abstract}
This article reports the findings of a case study on the implementation of Blackboard Learning Management System in the Department of English, Prince Sattam bin Abdulaziz University, Saudi Arabia. The study aims at exploring the effects of using Blackboard, an interactive computermediated learning environment, on English majors' writing proficiency and examining their attitudes towards the use of Blackboard. Three indicators were used, namely, accuracy, fluency and complexity to estimate students' writing proficiency. The Profile of Larsen-Freeman (2006) was employed to assess students' writing proficiency. Students' attitudes were measured through a questionnaire that is divided into three domains: (a) demographic and personal information, (b) implementation strategies of Blackboard and (c) students' attitudes towards Blackboard. Results of the study revealed a significant positive effect of using Blackboard on developing English majors' writing proficiency. In addition, students showed a positive attitude towards the use of Blackboard.
\end{abstract}

Key words: Blackboard, Writing Proficiency, Attitudes, English Majors

\section{INTRODUCTION}

In educational institutions at tertiary levels, the adoption of a learning management system has drastically transformed the teaching and learning practices. Learning Management Systems, such as Moodle, Blackboard or WebCT, have been recognized as online monitoring systems that have the potential to offer an effective and convenient online support to the traditional classroom teaching techniques (Black, 2008). Thus, it offers itself as a significant component of a mixed mode of interaction. In the context of this study, it is quite clear that despite the resistance to new web-based technologies and online learning systems, Blackboard has managed to offer greater pedagogical benefits to the instructor as well as to the learners. One of the advantages of adopting Blackboard-based instruction is its ubiquitous accessibility to both parties, that is, to the instructor and to the learner.

Overwhelmed by the desire to exploit the potentials of Blackboard to help EFL learners to master language skills and to achieve language proficiency, the university has supported the growing tendency to integrate such interactive computer-mediated learning environment in language instruction and to investigate its effect on developing English majors' language skills and proficiency. In this regard, developing writing proficiency represents a real challenge to English majors who struggle to produce quality writing. There is a general consensus that writing proficiency is multi-componential in nature and its main core can be captured in terms of three dimensions: accuracy, fluency, and complexity (Fellner \& Apple, 2006).

Using accuracy, fluency and complexity as indicators of learners' oral and written proficiency dates back to the 1980 s when second language research has made a distinction between fluency and accuracy in L2 usage (Housen \& Kuiken, 2009). Brumfit (1984) is one of the pioneers who used the accuracy-fluency dichotomy to distinguish two kinds of activity: accuracy-oriented activities and fluency-oriented activities. Complexity, the third dimension, added later by Skehan (1989) who created a model in which accuracy, fluency and complexity became the three basic proficiency indicators.

\section{Problem of the Study}

English majors' poor writing is clearly observed in writing classes and is strongly emphasized by students' low scores in standardized writing exams. The current teaching practices that do not provide students with enough opportunity to practice writing or sufficient feedback to improve the quality of their writings might be, to a great extent, the reason for such poor writing performance. Consequently, changing the instructional practices through the use of Blackboard Learning Management System is recommended as a way to deliver knowledge in a creative manner and to provide students with various opportunities to enhance their writing proficiency. Another aspect of the problem is related to students' attitudes towards the use of Blackboard. When Prince Sattam bin Ab- 
dulaziz University procured the Blackboard Vista license, many students in different disciplines reported passive attitudes towards Blackboard considering it as an obstruction to their learning. Therefore, the need arose to investigate English majors' attitudes towards the use of Blackboard in learning language skills. There is also a need to investigate various limitations in the application of the Blackboard software and the extent to which these limitations represent a distraction to its implementation in the classroom or faceto-face teaching. This study highlights factors related to learning environment, students' own styles of learning, their exposure to the internet and online services, problems that students face, such as time and pressure, anxiety and fear of missing deadlines. Such issues contribute to building up student's attitudes towards Blackboard. Hence, it is important to study students' attitude towards Blackboard in this study, because attitude is often determined as a barrier to the accessibility and usability of Blackboard (Al Turki, Aldraiweesh \& kinshuck, 2016). The present study attempts to find an answer to all these issues and challenges.

\section{Significance of the Study}

The significance of the present study lies in two points: (1) exploring the state of application of Blackboard especially after the university administration has given priority to the activation of Blackboard in all disciplines. Thus, the results of this study may provide a scientific database for making decisions regarding developing successful implementation strategies of Blackboard use; and (2) investigating the effect of using Blackboard on developing students' writing proficiency.

\section{Questions of the Study}

The present study seeks to answer the following two main questions:

1. What is the effect of using Blackboard on English majors' writing proficiency?

2. What are the English majors' attitudes towards the use of Blackboard?

\section{LITERATURE REVIEW}

A number of studies have been conducted to investigate students' attitudes and perceptions in the context of Blackboard use or any other online Learning Management System in Saudi Arabia. Alqurashi (2005), for instance, investigated the impact of Blackboard software as a collaborative learning technique in Saudi Arabia universities. Alqurashi's study compared the achievement of two groups of students; the first studied through face to face learning mode and the second through web-based mode. The results of the study did not show any significant differences between the two groups. The author interpreted the results, claiming that it might be because collaborative learning is a new teaching technique in the Saudi environment; secondly, the universities lack adequate computer labs and resources and therefore cannot have full access to the Internet.
Hussein (2011) and Al Turki et al (2016) investigated the instructors' attitudes, in Saudi universities, towards using E-learning Management System, JUSUR, developed by National Center for E-learning. These studies also revealed no difference in instructors' attitudes towards the implementation of JUSUR. A few other studies (Al-Khalifa, 2012; Choudhury, 2015; Hussein, 2016) examined various variables such as motivation and improvement of language skills with respect to the integration of Blackboard and other online Learning Management Systems. Similarly, Ja'ashan (2015) carried out a case study to analyze EFL students' perceptions and attitudes towards Blended Learning in the University of Bisha, Saudi Arabia. The results of his study, however, revealed students' positive attitudes towards Blended Learning but also emphasized that students should take more responsibility for their own learning process. In addition, students should develop self-learning strategies, independent thinking and ability to decide when to use the Learning Management System. Ja'ashan's study also concludes that the Learning Management System used in Blended Learning is as effective as face to face learning techniques for developing and improving knowledge and skills.

Similar studies (Inversini et al, 2006; Kim \& Seo, 2009) have confirmed the significance correlation between the Blackboard and the learning objectives of study courses. Sherman (2009) conducted a study on the usability of Blackboard and derived positive results, stating that the Blackboard software helped in the accessibility of information and the achievement of target objectives. The study also showed that Blackboard menu was helpful in engaging learners and enabling them to navigate and download materials easily. A similar study by Al-Mouh et al. (2014) stated that accessibility is important for content creation and transmission that, eventually, lead to realizing learning objectives. On the contrary, Goh et al. (2014) hold the opinion that Blackboard lacks enough sequential keyboard functional accessibility. Thus both studies hint at the essential characteristics required for the implementation of Blackboard in an instructional situation.

One of the barriers that faces the successful implementation of Blackboard is the design of the Blackboard software. Badwood and Steenkamp (2013) stated that design affects usability as well as accessibility and proves to be a great hindrance to the implementation of the Blackboard software. A good design can ease the use of the Blackboard software and increase the interaction with both learners and instructors. Students can receive and transmit interactional materials much faster and more easily. The usability and accessibility issues are closely connected to implementation. Badwood and Steenkamp (2013) urge that any learning management system must possess a simplified structure, an interactive interface design, a good organization and standard measures of application in order to facilitate an effective implementation.

There are several other studies which have reiterated the use of Blackboard or a similar learning management system in university education. Flowers (2001) highlighted the need to blend the online learning with classroom teaching. Schmidt (2001) investigated the suitability of multimedia, 
such as CDROM or internet for web-based learning. Woods (2004) also conducted a study on students' perceptions towards web-based instruction. Kim and Seo (2005) examined students' attitudes towards WebCT or CMS (a Blackboard developed Management system course) at the University of Houston. The results of the study revealed a positive attitude towards the online learning management system as it raised the quality of interaction and feedback. All these studies have shown a significant correlation between students' satisfaction and web-based instruction.

With regard to understanding learners' attitudes toward Blackboard, Brown (2007) found out that Blackboard based-instruction is in harmony with students' learning styles, allowing them to access the learning material at their own pace. One of the major causes of negative attitudes among the learners is that they suffer from performance anxiety as they cannot afford to make mistakes and wish to avoid embarrassment. To cope up with performance anxiety, Blackboard has played a big role in making face-to-face modes easier by allowing the participation of both the instructor and the learners through blackboard-based modes. Moreover, it also enables the weak and average learners to access the learning material prior to the lecture and, if needed, use it after the lecture too. This helps not only to alleviate the performance anxiety but also to increase students' comprehension and build up a positive attitude.

There are also a few other demotivating factors that are responsible for developing users' negative attitudes towards the Blackboard software. Melton (2004) provides a list of these factors which includes teacher's characteristics, such as his capabilities, his knowledge of e-learning, prior experience with educational technology, and learning management system features and accessibility. All these factors contribute to creating students' attitudes. If these characteristics are positive, the attitude is positive too, but if there are negative traits, the learners may develop negative attitudes. Additionally, technology may pose another demotivating factor responsible for negative attitudes which occurs in the form of a slow internet connection or computers with old configurations. There are also technological issues related to network, software failure, or disruption of Internet connection during teaching. While the teacher and learners spend time repairing the connection or fixing the issue, there occur demotivation and negative attitudes towards the software.

\section{METHOD}

\section{Instruments of the Study}

\section{Writing Proficiency Test}

To assess students' writing proficiency, the researcher designed a test in which students were asked to write a descriptive essay. Students were given an hour to submit their essays. The optimal time of the test was determined at the pilot stage. Students' essays were scored and analyzed quantitively through the use of the Profile of Larsen-Freeman (2006) which is based on T-units. According to Hunt (1965), T-unit is "one main clause with all subordinate clauses attached to it" used as an objective and reliable tool for as- sessing both oral and written language proficiency in terms of three indicators: (1) accuracy that refers to the proportion of error-free T-units of all T-units in the text, (2) fluency that refers to the average number of words in a text and the average number of T-units per text, and (3) complexity that refers to number of clauses per T-unit and dependent clause percentage.

\section{Questionnaire of students' attitudes towards blackboard}

In this study, a well-structured questionnaire divided into 3 sections was administered and given to 30 English majors. The objective of distributing the questionnaire was to identify the issues and challenges found in the implementation of Blackboard as well as students' attitudes towards the use of Blackboard. The face validity of the questionnaire was achieved through submitting it to ten experts who reported the suitability of the questionnaire for assessing students' attitudes. The first section of this questionnaire addresses issues related to age, gender, and frequency of computer use or any device to access Blackboard. The second section deals with Blackboard accessibility and implementation. The five-point Likert Scale was used to identify the accessibility and implementation status. The third section of the questionnaire concerns students' attitudes to examine how they evaluate the use of Blackboard and whether it facilitates or distracts their learning.

\section{Design of the Study}

Due to the nature of the study, one group pre-test/post-test design was utilized in the present study. A writing proficiency test and a questionnaire of students' attitudes towards the use of Blackboard were designed and administered on the students before and after the experiment.

\section{Sample of the Study}

Thirty students, studying a writing course using Blackboard, from level four were randomly chosen. They were regular students at the Department of English, College of Science and Humanities, Prince Sattam bin Abdulaziz University, Saudi Arabia.

\section{RESULTS AND DISCUSSION}

\section{Results of the Writing Proficiency Test}

The writing proficiency test was administered before and after the experiment. To measure the effect of using Blackboard on students' writing proficiency, SPSS program was utilized to analyze the students' scores in three aspects of writing proficiency: accuracy, fluency and complexity. First, students' writing accuracy was measured by comparing the means of error-free T-unit in students' essays before and after the experiment. Results, displayed in Table 1, indicated a significant increase in the number of error-free T-unit in favor of the post administration.

Another measurement of students' writing accuracy was the number of error-free clauses. Results of the paired-sam- 
ples t-test, displayed in Table 2, indicated a significant increase in the number of error-free clauses in favor of the post administration.

Second, students' writing fluency was measured by comparing the means of number of words in students' essays before and after the experiment. Results, displayed in Table 3, indicated a significant increase in the number of words in favor of the post administration.

Another measurement of students' writing fluency was the average number of T-units in a text. Results of the paired-samples t-test, displayed in Table 4, indicated a significant increase in the number of T-units in favor of the post administration.

Third, students' writing complexity was measured by comparing the means of number of clauses per T-unit in students' essays before and after the experiment. Results, displayed in Table 5, indicated a significant increase in the number of clauses per T-unit in favor of the post administration.
Another measurement of students' writing complexity was dependent clause percentage in a text. Results of the paired-samples t-test, displayed in Table 6, indicated a significant increase in the dependent clause percentage in a text in favor of the post administration.

According to the aforementioned results, a positive effect of using Blackboard on developing English majors' writing proficiency was found as there was a statistically significant difference between students' scores in pre-and post-test in favor of the post administration.

\section{Results of the Questionnaire of Students' Attitude towards Blackboard}

This questionnaire was based on a previous study carried by Lukow \& Ross (2003) to investigate students' attitudes towards the use and accessibility of technology. However, it was

Table 1. Means, standard deviation and t-value of students' writing accuracy in terms of number of error-free T-unit

\begin{tabular}{lcccccc}
\hline Writing proficiency test/ accuracy index & No. & Mean & SD & t.value & df & Sig. (2-tailed) \\
\hline Pre & 30 & 13.40 & 3.729 & 16.778 & 29 & $0.01^{*}$ \\
Post & & 31.97 & 7.819 & & & \\
\hline
\end{tabular}

Table 2. Means, standard deviation and t-value of students' writing accuracy in terms of number of error-free clauses

\begin{tabular}{lcccccc}
\hline Writing proficiency test/ accuracy index & No. & Mean & SD & t.value & df & Sig. (2-tailed) \\
\hline Pre & 30 & 48.37 & 8.252 & 13.915 & 29 & $0.01^{*}$ \\
Post & & 72.30 & 11.164 & & & \\
\hline
\end{tabular}

Table 3. Means, Standard Deviation and t-value of students' writing fluency in terms of the average number of words in a text

\begin{tabular}{lcccccc}
\hline Writing proficiency test/ fluency index & No. & Mean & SD & t.value & df & Sig. (2-tailed) \\
\hline Pre & 30 & 208.30 & 45.271 & 18.345 & 29 & $0.01^{*}$ \\
Post & & 423.70 & 50.141 & & & \\
\hline
\end{tabular}

Table 4. Means, standard deviation and t-value of students' writing fluency in terms of the average number of T-units in a text

\begin{tabular}{lcccccc}
\hline Writing proficiency test/ fluency index & No. & Mean & SD & t.value & df & Sig. (2-tailed) \\
\hline Pre & 30 & 28.50 & 6.285 & 15.374 & 29 & $0.01^{*}$ \\
Post & & 49.27 & 5.729 & & & \\
\hline
\end{tabular}

Table 5. Means, standard deviation and t-value of students' writing complexity in terms of the average number of clauses per T-unit

\begin{tabular}{lcccccc}
\hline Writing proficiency test/ complexity index & No. & Mean & SD & t.value & df & Sig. (2-tailed) \\
\hline Pre & 30 & 1.40 & 0.675 & 7.131 & 29 & $0.01^{*}$ \\
Post & & 2.50 & 0.682 & & & \\
\hline
\end{tabular}

Table 6. Means, standard deviation and t-value of students' writing complexity in terms of dependent clause percentage

\begin{tabular}{lcccccc}
\hline Writing proficiency test/ complexity index & No. & Mean & SD & t.value & df & Sig. (2-tailed) \\
\hline Pre & 30 & 23.67 & 3.032 & 42.141 & 29 & $0.01^{*}$ \\
Post & & 52.67 & 1.668 & & & \\
\hline
\end{tabular}


Table 7. Means, Standard Deviation, item-total correlations of students' responses

\begin{tabular}{|c|c|c|c|}
\hline & $\mathbf{M}$ & S.D. & $\mathbf{r}$ \\
\hline \multicolumn{4}{|l|}{ Domain 1: Students' beliefs } \\
\hline Blackboard increases my achievement. & 4.25 & 1.44 & 0.72 \\
\hline Blackboard facilitates work greatly. & 4.23 & 1.49 & 0.79 \\
\hline I am willing to get more training about how to use it. & 4.21 & 1.45 & 0.76 \\
\hline It provides a great benefit in learning. & 4.21 & 1.34 & 0.76 \\
\hline I get help from Blackboard when I have a problem. & 4.19 & 1.34 & 0.71 \\
\hline I discuss with my colleagues the various ways to use blackboard. & 3.52 & 1.47 & 0.57 \\
\hline Blackboard leads to good changes in the course applications. & 4.225 & 1.43 & 0.77 \\
\hline Blackboard helps in clarifying the material content. & 4.21 & 1.44 & 0.78 \\
\hline I believe that Blackboard will be a necessity for all students in future. & 4.12 & 1.40 & 0.81 \\
\hline My readings of courses became better through Blackboard usage. & 4.11 & 1.39 & 0.75 \\
\hline Doing home assignments through Blackboard is better and easier. & 4.20 & 1.42 & 0.76 \\
\hline The activities used in Blackboard are clear and useful & 3.90 & 1.40 & 0.72 \\
\hline \multicolumn{4}{|l|}{ Domain 2: The effect of Blackboard on learning } \\
\hline Blackboard helps me to organize the course continuously. & 4.115 & 1.39 & 0.78 \\
\hline Blackboard software provides additional educational sources. & 4.15 & 1.35 & 0.79 \\
\hline Blackboard allows the learner to learn without the need to attend the university. & 4.25 & 1.39 & 0.62 \\
\hline The information through Blackboard is more than what I get in the usual class & 4.15 & 1.40 & 0.62 \\
\hline Blackboard helps me to view information about courses before they are explained. & 3.95 & 1.41 & 0.78 \\
\hline My learning improved in classroom discussions after I started using Blackboard. & 4.29 & 1.42 & 0.79 \\
\hline Blackboard helped me to self-learning. & 4.15 & 1.42 & 0.72 \\
\hline Blackboard supports in lifelong learning. & 4.21 & 1.42 & 0.73 \\
\hline I like doing courses uploaded on Blackboard. & 4.21 & 1.41 & 0.71 \\
\hline Blackboard helps me to learn without commitment at any place or time. & 4.15 & 1.42 & 0.73 \\
\hline \multicolumn{4}{|l|}{ Domain 3: Affective factors } \\
\hline I feel enjoyed when someone speaks to me about Blackboard and its utilities. & 4.22 & 1.43 & 0.72 \\
\hline Blackboard allows students to get an individual learning environment. & 4.21 & 1.42 & 0.73 \\
\hline Blackboard helps students participate in effective integration of educational sources. & 4.21 & 1.45 & 0.69 \\
\hline Blackboard increases the interaction between teacher and learner. & 4.22 & 1.49 & 0.67 \\
\hline Blackboard helps me in achieving better results compared to the usual learning. & 4.22 & 1.44 & 0.67 \\
\hline Blackboard makes learning simple. & 4.24 & 1.45 & 0.71 \\
\hline Blackboard provides an interesting learning. & 4.24 & 1.41 & 0.70 \\
\hline Blackboard provides quick delivery of information to students. & 4.21 & 1.43 & 0.71 \\
\hline
\end{tabular}

modified to meet the requirements of the present study. There were three sections of the questionnaire: (a) demographic and personal information, (b) implementation strategies of Blackboard and (c) students' attitudes towards Blackboard.

In the first section, it was evident that all participants are males aged between 18 and 25 . The great majority of participants $(35 \%)$ are aged between 22 and 23 years, $26.4 \%$ at the age of 20 and 21 and $23.9 \%$ between 24 and 25. Participants were also asked to record their computer skills and familiarity with Blackboard application on a 5-point scale, with the score of 5 being (expert) and 1 as (novice). The findings revealed that $48 \%$ of the participants considered the level of their computer and internet skills as 4 and above.

The second section dealt with implementation strategies of Blackboard and evidence was collected on a 5-point Likert scale. With regard to use of internet, $82.5 \%$ recorded that they used it for more than one hour a day and $76 \%$ said they used Word, PowerPoint presentations and "one to one email" to produce more than one document a day. Similarly, a very high percentage $(81 \%)$ recorded their interest in interacting with Blackboard and found its accessibility quick and timely. The Cronbach Alpha for this section of the questionnaire was calculated as .879 .

The third section of the questionnaire addresses the participants' attitudes towards the use of Blackboard to determine whether it facilitates or obstructs their learning. A scale guided the participants whose range spanned from 1 to 5 on the scale. A total of 30 items were used to deal with issues in three domains: students' beliefs, effect of Blackboard on learning and affective factors.

These 30 items were designed to assess factors such as the level of facilitation, learners' willingness and perception, 
Table 8. Paired-samples t-test results of the questionnaire of students' attitudes towards the use of blackboard

\begin{tabular}{lcccccc}
\hline $\begin{array}{l}\text { Questionnaire of students' attitudes towards the use of } \\
\text { blackboard }\end{array}$ & No. & Mean & SD & t.value & df & Sig. (2-tailed) \\
\hline Pre & 30 & 66.70 & 8.57 & 20.7 & 29 & $0.01^{*}$ \\
Post & & 102.60 & 2.74 & & & \\
\hline
\end{tabular}

$* \mathrm{p}<.01$.

learners' acceptance of Blackboard as an instructional and evaluation medium and a useful aid to the learning courses. The alpha reliability was highly accepted $(\alpha=0.96)$ and items' coefficients show that the values ranged from 0.57 to 0.81 . This study was of exploratory nature; hence, reliability of the scales was deemed adequate.

Based on the 5-point Likert scale, the mean of all items, displayed in Table 7, exceeds the anchor point (3.5). The highest mean (4.25) with the SD of 1.44 is found in item 1 (Blackboard increases my achievement). This result shows students' positive beliefs in using Blackboard for academic achievement. On the other hand, the lowest mean (3.52) with SD of 1.47 occurred in item 6 (I discuss with my colleagues the various ways to use blackboard). This result shows that students face problems and search for their solutions. Many items of the questionnaire seek to figure out whether or not Blackboard supports self-learning and creates an individual learning environment that could be managed by learners' own pace.

Last but not the least, this study attempted to investigate English majors' attitudes towards Blackboard if it is blended with face-to-face or traditional classroom teaching style. When combined with classroom teaching, a majority (81\%) felt that it offered assistance to learning. This is evidence for positive attitudes towards the acceptance of a blended learning approach, where Blackboard acts as an online learning monitoring system, closely blended with the classroom teaching. The learners felt that it was very beneficial and they could have more contact with the instructor.

To quantitatively assess the effect of Blackboard on students' attitudes, a Paired-samples t-test was conducted to compare the mean scores of the students before and after the experiment. The results, displayed in Table 8, showed a statistically significant difference in the students' scores for the pretest $(M=66.70, S D=8.57)$ and for posttest $(M=102.60$, $\mathrm{SD}=2.74) ; \mathrm{t}(29)=20.7, \mathrm{p}=0.01$ in favor of the post application. These findings affirmed students' positive attitudes towards the use of Blackboard.

\section{CONCLUSION}

A large number (48\%) of students recorded their skill level as 4 or above. This revealed that the current sample possessed high computer skills and familiarity with Blackboard application. This result was supported by findings of the second and the third sections in which students were found to be proficient users of several types of internet tools and resources, which they regularly utilized to carry out their learning tasks. An interesting point about this study is that the mean score of students' attitudes towards the use of Blackboard is in the positive range, which is consistent with the results of a prior study on the same topic (Lukow \& Ross, 2003).

Analyzing students' responses showed evidence that they are satisfied with the use of Blackboard and its accessibility as it helps them achieve the learning objectives. Besides the two-way interactive activities embedded in Blackboard, students also felt that other resources, such as emails, PowerPoint, and course websites supplement and support the effective use of Blackboard. Hence, further investigation is needed to justify such issues. The medium positive correlation found between usability and accessibility and attitude total score of respondents is also encouraging for university administration to continue their efforts to spread the use of Blackboard. However, a deeper investigation is required to support these findings since there are still a few students who may not be using computers and internet and hence Blackboard is not accessible to them. It is important to find out how to resolve this issue and consider the needs of all learners in the program.

It is recommended that further research should be carried out to replicate this study over different populations and attempts may be made to validate usability, accessibility and students' attitudes towards the use of Blackboard. A similar study may also be carried out to investigate the effect of using Blackboard on other language skills. A study may also be conducted to investigate barriers to the usability of Blackboard or what demotivating factors prevent learners from showing positive attitudes. Finally, the university should also encourage staff members to use Blackboard as a learning tool to present material in a creative manner and to establish better communication with students.

\section{REFERENCES}

Al Turki, U., Aldraiweesh, A. \& Kinshuck, X. (2016). Evaluating the usability and accessibility of LMS "Blackboard" at King Saud University, Contemporary Issues in Education Research, 9(1), 33-44.

Al-Khalifa, H. (2010). A First step in evaluating the usability of JUSUR Learning Management System. Paper Presented at the $3^{\text {rd }}$ Annual Forum on e-Learning Excellence in the Middle East 2010: Bringing Global Quality to a Local Context. February 1 st- $3^{\text {rd }}$, Dubai, U.A.E.

Al-Mouh, N., Al-Khalifa, A. \& Al-Khalifa, H. (2014). A first look into MOOCs accessibility: The case of Coursera. Computers Helping People with Special Needs In: Lecture Notes in Computer Science. Springer International Publishing, 8547, 145-152.

Alqurashi, F. (2005). Computer Supported Collaborative Learning in Composition Classrooms in Saudi Arabia. Doctoral Dissertation, Ball State University. 
Badawood, A. (2011). A systematic approach to faculty development towards improved capability in tertiary teaching in a blended learning environment. Doctoral Dissertation, Lawrence Technological University.

Black, E. (2008). Toolkit approach to integrating library resources into the learning management system. The Journal of Academic Librarianship, 34(6), 496-501.http:// doi.org/10.1016/j.acalib.2008.09.018.

Brown, D. (2007). Principles of language learning and teaching. ( $6^{\text {th }}$ ed.). White Plains, NY: Pearson.

Brumfit, C. (1984). Communicative methodology in language teaching: The roles of fluency and accuracy. Cambridge: Cambridge University Press.

Choudhury, M. (2015). Texts, contexts and motivational strategies in teaching literature to Saudi students. International Journal of English Language Teaching, 3(8), 19-35.

Flowers, J. (2001). Online learning needs in teaching technology education. Journal of Technology Education, 13(1), 17-30. https://doi.org/10.21061/jte.v13i1.a.2

Fellner, T. \& Apple, M. (2006). Developing writing fluency and lexical complexity with blogs. JALT CALL Journal, 2(1), 15-26.

Goh, W., Hong, J. \& Gunawan, W. (2014). Exploring lecturers' perceptions of learning management system: An empirical study based on TAM. International Journal of Engineering Pedagogy, 4(3), 48-54.

Housen, A. \& Kuiken, F. (2009). Complexity, accuracy, and fluency in second language acquisition. Applied Linguistics, 30(4), 461-473.

Hunt, W. (1965). Grammatical structures written at three grade levels. Urbana, IL: The National Council of Teachers of English.

Hussein H. (2011) Attitudes of Saudi universities faculty members towards using learning management system (JUSUR). TOJET: The Turkish Online Journal of Educational Technology, 10(2), 43-53.
Hussein, E. (2016). The effectiveness of using blackboard in improving the English listening and speaking skills of the female students at the University of Hail. Advances in Social Sciences Research Journal, 3(12), 81-93. https://doi.org/10.14738/assrj.312.2379.

Inversini, A., Botturi, L. \& Triacca, L. (2006). Evaluating LMS usability for enhanced e-learning experience. In E. Pearson \& P. Bohman (Eds.), Proceedings of ED-MEDIA 2006- World Conference on Educational Multimedia, Hypermedia and Telecommunications, 595-601, Orlando, FL USA.

Ja'ashan, M. (2015) Perceptions and attitudes towards blended learning for English courses: A case study of students at University of Bisha. English Language Teaching, 8(9), 40-50.

Kim, S., \& Seo, B. (2009). The development of e-learning platform for gifted children education. International Journal for Educational Media and Technology, 3(1), 39-51.

Larsen-Freeman, D. (2006). The emergence of complexity, fluency, and accuracy in the oral and written production of five Chinese learners of English. Applied Linguistics, 24(7), 590-619.

Lukow, J. \& Ross, C. (2003). How learning styles affect student attitudes toward technology. SCHOLE: A Journal of Leisure Studies and Recreation Education, 18(1), 67-80.

Melton, J. (2004). The CMS moodle: A heuristic evaluation. Paper presented at JALTCALL2004, Mito, Japan.

Schimidt, K. (2002). Classroom action research: A case study assessing students' perceptions and learning outcomes of classroom teaching versus on-line teaching. Journal of Industrial Teacher Education, 40(1), 45-59.

Sherman, P. (2009). UPA Salary Survey. New York: McGraw-Hill.

Skehan, P. (1989). Individual differences in second language learning. London: Edward Arnold.

Woods, G. (2004). Student perceptions of web-based technologies, principles of good practice, and multiple intelligences. Doctoral Dissertation, Alliant International University at San Diego. 